\title{
OECD Ülkelerinde Sağlık Harcamaları ile Kalkınma Arasındaki İlişki: Panel Veri Analizi
}

\author{
Mahmut Ünsal ŞAŞMAZ ${ }^{*}$ Hakkı ODABAŞ ${ }^{* *}$ Yunus Emre YAYLA***
}

$\ddot{O} Z$

Sağllk harcamalarl ülkelerin kalkınma sürecinde önemli bir yer tutmaktadır. Beşeri bir yatırım türü olması nedeniyle sağlık harcamaları kalkınmanın sağlanması açısından önemlidir. Bu nedenle sağllk harcamaları ile kalkınma arasındaki ilişkiyi belirlemek önemli olmaktadır. Çalışmada panel veri analizinden yararlanılarak 34 OECD ülkesinde 2000-2015 yilları arasinda sağlık harcamalarının kalkınma üzerindeki etkisi araştırılmıştır. Çalışma sonuçlarına göre, sağlık harcamaları ile kalkınma arasında uzun vadeli bir ilişki olduğu sonucuna ulaşılmıştır. Bununla birlikte sağllk harcamalarının kalkınma üzerinde pozitif bir etki meydana getirdiği tespit edilmiştir. Diğer yandan sağllk harcamaları ile kalkınma arasında çift yönlü nedensellik ilişkisi olduğu belirlenmiștir.

Anahtar Kelimeler: Sağlık, Harcama, Kalkınma, OECD

JEL Sinıflandırması: 115, O15, C15

\section{Relationship Between Health Expenditures and Development In The OECD Countries: Panel Data Analysis}

\begin{abstract}
Health expenditures have an important place in the development process of countries. As it is a human investment type, health expenditures are important in terms of development. Therefore, the relationship between health expenditures and development needs to be demonstrated. In this study, the effect of health expenditures on development was investigated in 34 OECD countries between 2000 and 2015 by using panel data analysis. According to the results of the study, it is concluded that there is a long-term relationship between health expenditures and development that health expenditures have a positive effect on development. On the other hand, there was a two-way causality relationship between health expenditures and development.
\end{abstract}

Key Words: Health, Expenditure, Development, OECD

JEL Classification: I15, O15, C5

\section{GíRiş}

Kalkınma, ekonomik büyüme ile ilişkili bir kavram olmakla birlikte daha geniş kapsamlıdır. Milli gelir artışını ifade eden ekonomik büyüme kavramının yanında kalkınma sosyo-kültürel, yapısal, kurumsal gibi birçok alanda gelişmeyle

\footnotetext{
* Dr. Öğr. Üyesi, Uşak Üniversitesi, İktisadi ve İdari Bilimler Fakültesi, Maliye Bölümü Öğretim Üyesi, mahmut.sasmaz@usak.edu.tr ORCID bilgisi: 0000-0001-9485-3933

*** Prof. Dr. Ankara Yıldırım Beyazıt Üniversitesi, Siyasal Bilgiler Fakültesi, Maliye Bölümü, hakkiodabas@gmail.com ORCID bilgisi: 0000-0001-9145-9391

*** Afyon Kocatepe Üniversitesi, Sosyal Bilimler Enstitüsü, Maliye Anabilim Dalı, Doktora Öğrencisi, yunusemre.yayla@outlook.com ORCID bilgisi: 0000-0003-1924-4550
} 
birlikte insani gelişmeyi de kapsamaktadır. Bununla birlikte ekonomik büyüme kalkınmanın olmazsa olmazı konumundadır.

Sağlık harcamaları beşeri bir yatırım olması nedeniyle bireylerin refahı ve gelişimi açısından önem taşımaktadır. Beşeri bir yatırım türü olan sağlık harcamaları sonucunda sağlıklı bir neslin varlığı, ülkelerin kalkınma sürecinde önemli rol oynamaktadır. Başka bir ifadeyle, kalkınma açısından önem taşıyan beşeri sermayenin içerisinde yer alan sağlık harcamaları bu açıdan kalkınma sürecine destek olabilmektedir.

Gelişmekte olan ülkelerin bir kısmında sağlık alanında belirli sıkıntılar yaşanabilmektedir. Bu ülkelerde insani bir yatırım türü olan sağlık harcamalarının yetersizliği ülkede yaşayan bireylerin yaşamlarını zorlaştırmaktadır. Bu ülkeler, kaynak sıkıntısı yaşamaları nedeniyle sağlık alanına yeteri kadar harcama ayıramamaktadırlar. Diğer yandan temel besin maddelerine erişim güçlügü ile sağlıksız koşulların varlığ 1 sağlık harcamalarının yetersiz kalmasında temel nedenlerden olmaktadır. İnsani gelişmeyi dolaylı olarak etkileyen sağlık harcamalarının yetersiz kalması ülkelerin insani gelişmesini güçleştirmektedir. $\mathrm{Bu}$ nedenle ülkelerin sağlı harcamaları ile kalkınma arasındaki ilişkiyi incelemek önem arz etmektedir.

$\mathrm{Bu}$ çalışmada öncelikle konunun daha iyi kavranabilmesi için sağlık harcamaları ve kalkınma hakkında bilgi verilmiştir. Daha sonra sağlık harcamalarının kalkınma üzerindeki etkisi ile ilgili yapılan çalışmaların literatür taramasına yer verilmiştir. Takip eden bölümde panel veri analizinden yararlanılarak 34 OECD ülkesinde 2000-2015 döneminde sağlık harcamalarının kalkınma üzerindeki etkisi incelenmiştir. Son kısımda ise yapılan ekonometrik analiz sonuçlarına göre bulgular değerlendirilmiş ve öneriler sunulmuştur.

\section{SAĞLIK HARCAMALARI ve KALKINMA}

$\mathrm{Bu}$ bölümde öncelikle sağlık harcamaları daha sonra kalkınma ile ilgili teorik bilgilere yer verilmiştir.

\section{A. Sağlık Harcamaları}

Sağlık sektörü insani bir yatırım türü olduğundan ülkeler açısından önem arz etmektedir. Sağlık koşullarının iyileşmesi ile birlikte daha iyi sağlık hizmetleri sunmak sosyal ve ekonomik gelişmenin temel yönlerinden birisidir. Bundan dolayı, sağlık sektörüne yatırım yapmak tıpkı diğer sektörler gibi, altyapı yatırımları arasında planlı insan kaynakları gelişimi modeli olarak kabul edilmektedir (Razmi vd. 2012). Dünya'da insani gelişme açısından kalkınma sürecinde, sağlığa her zamankinden daha fazla önem verildiği bilinmektedir. Bunun sebebi, sağlık insani gelişmenin birincil boyutunu ortaya koyan insan özelliklerinin oluşumuna işaret etmektedir (Mirahsani, 2016: 373).

Nitekim kalkınma açısından en önemli gösterge olan İnsani Gelişmişlik Endeksi'nin bileşenleri arasında sağlık düzeyi de yer almaktadır. Toplumun sağlık düzeyinin iyileşmesi sonucunda, belli ekonomik faydalar oluşmakta ve sağlık düzeyi ile ekonomik gelişme arasında karşılıklı ilişki ortaya çıkmaktadır (Günsoy, 2005: 36). Sağlık harcamalarında artış yaşanması sonucunda bireylerin yaşam süresi ve beklentisi artmaktadır. Böylece bireyler sağlıklı olması sonucunda 
yaşadığı ülkeye katkı sağlayabilmektedir. Beşeri sermayenin önemli faktörlerinden olan sağlık, ekonomik faaliyetlerde bireyin eğitimi kadar önem taşımaktadır (Kamacı ve Yazıcı, 2017: 53-54). Çünkü daha sağlıklı bireyler toplumun emek verimliliğini arttırmaktadır. Diğer taraftan sağlık koşullarının iyileştirilmesi ile birlikte daha sağlıklı bir toplum oluşacak ve böylece iyi bir yaşam standardına sahip olunacaktır (Gönel, 2013:144).

Kalkınma açısından önemli olan sağlık politikalarında ve sağlık harcamalarında süreklilik önem arz etmektedir. Toplum sağlığının iyileştirilmesi ile ilgili çalışmalar yapan Dünya Sağlık Örgütü uluslararası alanda faaliyet gösteren önemli bir kuruluştur. Dünya Sağlik Örgütü'ne üye devletler, genel sağl1k kapsamını sağlamak ve sürdürmek amacıyla sağlık finansman sistemini geliştirmeyi hedeflemişlerdir. Sağlık finansmanında yer alan konular arasında; sağlık sigortasının hakkaniyete uygun olması, kaynakların en iyi şekilde kullanılması ve hastalıkları sağlığın mali sonuçlarından koruyan sağlık için yeterli fonların artırılması yer almaktadır (World Health Organization, 2014: 2).

\section{B. Kalkınma}

Klasik İktisadi Doktrine göre kalkınma, ekonomik büyüme içinde doğal yolla ve kendiliğinden gelişmektedir. Oysa kalkınma, ekonomik büyümeyle (milli gelir artışının) birlikte sosyal, siyasal, kültürel vb. alanları da kapsayan genel boyutlu bir yapısal dönüşümü ifade etmektedir (İlkin, 1983: 59). Kalkınma, bireylerin yaşam düzeyleri, özgüvenleri, özgürlügüü üzerinde etkili olarak onları arttıran ve tüm bireylerin yaşamları ile birlikte yeteneklerini geliştiren bir süreç olmaktadır (Todaro ve Smith, 2011: 5).

Ülkelerin kalkınma düzeylerinin ölçülmesinde okur-yazarlık oranı, yaşam beklentisi, gelir düzeyi, çocuk ölümleri ile şehirleşme oranı vb. göstergeler kullanılmaktadır. Dünya Bankası ve OECD gibi kurumlar ülkelerin kalkınmışlık sıralamasında milli geliri, kişi başına düşen geliri ve satın alma gücüne göre kişi başına düşen geliri dikkate almaktadır. Ayrıca bu tekil göstergelerle birlikte bütün göstergelerin birlikte değerlendirildiği endeksler mevcuttur (Yıldız, 2016: 68).

İnsani Gelişmişlik Endeksi ülkelerin insani gelişme düzeyini göstermesi açısından önemlidir. Birleşmiş Milletler tarafından hesaplanan İnsani Gelişmişlik Endeksi; uzun ve sağlıklı bir yaşam sürebilme, bilgi edinebilme ile iyi bir yaşam standardı elde edebilme durumlarını değerlendirerek insani gelişmeyi ölçmektedir ${ }^{1}$ (Human Development Report, 2016: 3). İnsani Gelişme Raporu'nda insani gelişme; bireylerin seçimlerinin genişletilmesi ve ulaştıkları refah düzeyinin geliştirilmesi süreci olarak tanımlanmaktadır (Srinivasan, 1999: 309).

Ülkelerin insani gelişme düzeyi, İnsani Gelişmişlik Endeksinin (İGE) 0,00 ile 1,00 arasındaki aldığ değere göre belirlenmektedir. Ülkenin İGE değeri en yüksekteki 80-100 aralığındaysa "Çok Yüksek Düzey İnsani Gelişme" grubunda, 70-80 aralığındaysa "Yüksek Düzey İnsani Gelişme" grubunda, 55-70

\footnotetext{
${ }^{1}$ Birleşmiş Milletler Kalkınma Programı insani gelişmenin daha iyi saptanabilmesi ve ortaya konulabilmesi için Eşitsizliğe Uyarlanmış İGE, Cinsiyete Dayalı İGE, Toplumsal Cinsiyet Eşitsizliği Endeksi, Çok Boyutlu Yoksulluk Endeksi olmak üzere dört tane gösterge yayınlamaktadır. Detaylı bilgi için bkz. Human Development Report (2016)
} 
aralığındaysa "Orta Düzey İnsani Gelişme" grubunda ve en alttaki 00-55 aralığındaysa "Düşük Düzey İnsani Gelişme" grubunda yer almaktadır (Human Development Report, 2016: 198-201).

Tablo 1'de çalışmanın örneklemini oluşturan 34 OECD ülkesinin 2015 y1lı İnsani Gelişmişlik Endeksi'ne göre Dünya'daki insani gelişme sıralaması verilmiştir. Endeks değerlerine bakıldığında, 32 ülkenin "Çok Yüksek İnsani Gelişme" grubunda, 2 ülkenin ise "Yüksek İnsani Gelişme" grubunda yer aldığ görülmektedir. Norveç 0,949 'luk endeks değeri ile örneklem ülkeler arasında ve Dünya'da birinci sırada yer almaktadır. Örneklem grubu içerisinde Meksika ise 0,762 endeks değeri ile son sırada yer alırken Dünya'da yetmiş yedinci sıradadır.

Tablo 1: Çalışmada Kullanılan Örneklem Ülkelerde İnsani Gelişmişlik Endeksi Dünya Sıralaması (2015)

\begin{tabular}{|c|c|c|}
\hline İnsani Gelişme Suralaması & Ülkeler & İnsani Gelişmişlik Endeksi \\
\hline 1 & Norveç & 0,949 \\
\hline 2 & Avusturalya & 0,939 \\
\hline 2 & İsviçre & 0,939 \\
\hline 4 & Almanya & 0,926 \\
\hline 5 & Danimarka & 0,925 \\
\hline 7 & Hollanda & 0,924 \\
\hline 8 & İrlanda & 0,923 \\
\hline 9 & İzlanda & 0,921 \\
\hline 10 & Amerika & 0,92 \\
\hline 10 & Kanada & 0,92 \\
\hline 13 & Yeni Zelanda & 0,915 \\
\hline 14 & İsveç & 0,913 \\
\hline 16 & İngiltere & 0,91 \\
\hline 17 & Japonya & 0,903 \\
\hline 18 & G. Kore & 0,901 \\
\hline 19 & İsrail & 0,899 \\
\hline 20 & Lüksemburg & 0,898 \\
\hline 21 & Fransa & 0,897 \\
\hline 22 & Belçika & 0,896 \\
\hline 23 & Finlandiya & 0,895 \\
\hline 24 & Avusturya & 0,893 \\
\hline 25 & Slovenya & 0,89 \\
\hline 26 & İtalya & 0,887 \\
\hline 27 & İspanya & 0,884 \\
\hline 28 & Çekya & 0,878 \\
\hline 29 & Yunanistan & 0,866 \\
\hline 30 & Estonya & 0,865 \\
\hline 36 & Polonya & 0,855 \\
\hline 38 & Şili & 0,847 \\
\hline 40 & Slovakya & 0,845 \\
\hline 41 & Portekiz & 0,843 \\
\hline 43 & Macaristan & 0,836 \\
\hline 71 & Türkiye & 0,767 \\
\hline 77 & Meksika & 0,762 \\
\hline
\end{tabular}

(Kaynak: Human Development Report, 2016: 198-199) 


\section{LITERATÜR}

Sağlık harcamaları ile kalkınma arasındaki ilişkiyi inceleyen çeşitli çalışmalar literatürde yer almaktadır (Bkz. Razmi vd. (2012), Mpofu (2013), Arslan vd. (2016), Li vd. (2017), Mirahsani (2016), Yalçın ve Çakmak (2016)). Sağlık harcamaları ile kalkınma arasındaki ilişkiyi belirlemek için yapılan çalışmalarda genellikle pozitif bir ilişki tespit edildiği görülmektedir (Bkz. Razmi vd. (2012), Arslan vd. (2016), Mirahsani (2016)). Kalkınmanın sağlanması açısından önemli ve gerekli olan ekonomik büyüme ile sağlık harcamaları arasındaki ilişkiyi inceleyen çalışmalarda literatüre dahil edilmiştir (Bkz. Heshmati (2001), Mishra ve Mishra (2015), Kamac1 ve Yazıc1 (2017), Şen vd. (2018)). Yapılan çalışmalarda ekonomik büyüme üzerinde sağlık harcamalarının genelde olumlu etkiye neden olduğu görülmektedir (Bkz. Heshmati (2001)). Sağlık harcamaları ile kalkınma arasındaki ve sağlık harcamaları ile ekonomik büyüme arasındaki ilişkiyi araştıran çalışmalar aşağıda özetlenmiştir;

Solow modeli dahilinde sağlık harcamaları ile ekonomik büyüme arasındaki ilişkiyi araştıran Heshmati (2001), nedensellik testi yöntemini kullanarak OECD ülkelerinde 1970-1992 dönemini kullanmıştır. Yapmış olduğu çalışma sonucunda, sağlık harcamaları ile ekonomik büyüme arasında olumlu bir ilişsinin varlığına ulaşmıştır. Diğer bir çalışmada Gyimah-Brempong ve Wilson (2004), panel veri analizi yöntemini kullanarak 21 Sahra altı Afrika ülkesinde 1975-1994 döneminde ve 23 OECD ülkesinde 1961-1995 döneminde sağlık ile ekonomik büyüme arasındaki ilişkiyi araştırmışlardır. Kişi başına düşen geliri yıllık artış oranını ekonomik büyüme göstergesi olarak kullanmışlardır. Yapmış oldukları çalışma sonucunda, ekonomik büyüme ile sağlık arasında olumlu ve güçlü bir ilişkinin olduğunu tespit etmişlerdir. Başka bir çalışmada Jha vd. (2001), panel veri analizi yöntemini kullanarak Hindistan'1n 14 eyaletinde 19571958 ile 1997 yılları arasında eğitim, sağlık ve diğer kalkınma faaliyetlerine ilişkin kamu harcamalarının yoksulluğun azaltılmasındaki etkisini araştırmışlardır. Çalışma sonucunda, eğitim, sağlik ve diğer kalkınma faaliyetlerine ilişkin kamu harcamalarının yoksulluğu azalttığını tespit etmişlerdir. Diğer bir çalışmada Suescún (2007), duyarlılık analizi yöntemini kullanarak 15 Latin Amerika ülkesinde 2000-2005 yılları arasında kamu harcamaları ve büyüme ile insani gelişme arasındaki ilişkiyi araştırmıştır. Çalışma sonucunda, hükümet altyapı harcamalarının diğer kamu harcamalarına göre (eğitim, sağlık, devlet tüketimi ve düşük gelirli hane halklarına transferler) büyüme ve insani gelişme üzerinde nispeten daha güçlü etkisinin olduğunu tespit etmiştir. Başka bir çalışmada Baltagi ve Moscone (2010), panel veri analizi yöntemini kullanarak 20 OECD ülkesinde 1971-2004 döneminde sağlı harcamaları ile gelir arasındaki ilişkiyi araştırmışlardır. Çalışma sonucunda sağlık harcamaları ile gelir arasında uzun dönemli bir ilişki tespit etmişlerdir.

Sağlık sistemleri ve insani gelişme düzeyleri arasındaki ilişkiyi araştıran Alin ve Marieta (2011), korelasyon analizi yöntemini kullanarak Avrupa Birliği ülkelerini örneklem olarak kullanmışlardır. Yapmış oldukları çalışma sonucunda, sağlık sistemi ile insani gelişme düzeyi arasında güçlü bir korelasyon ilişkisi 
tespit etmişlerdir. Benzer bir çalışmada Razmi vd. (2012), en küçük kareler yöntemini (OLS) kullanarak İran'da 1990-2009 döneminde hükümetin sağlık harcamalarının İnsani Gelişmişlik Endeksi üzerindeki etkisini araştırmışlardır. Çalışma sonucunda, hükümetin sağlık harcamaları ile İnsani Gelişmişlik Endeksi arasında anlamlı ve pozitif bir ilişki tespit etmişlerdir. Ayrıca, Granger nedensellik testi sonuçlarına göre, İran'da hükümetin sağlik harcamaları ve İnsani Gelişmişlik Endeksi arasında ikili bir ilişki olmadığını belirlemişlerdir. Diğer bir çalışmada Yardımcıoğlu (2012), panel veri analizi yöntemini kullanarak 25 OECD ülkesinde 1975-2008 yılları arasında sağlık (yaşam beklenti düzeyi) ile ekonomik büyüme arasındaki ilişkiyi araştırmıştır. Çalışma sonucunda, sağlık (yaşam beklenti düzeyi) ile ekonomik büyüme arasında uzun dönemde eşbütünleşme ilişkisi olduğunu, FMOLS test yöntemine göre değişkenlerin birbirini pozitif etkilediğini ve nedensellik testi sonucuna göre değişkenler arasında çift yönlü nedensellik ilişkisinin varlığını belirlemiş̧tir. Başka bir çalışmada Mpofu (2013), regresyon analizi yöntemini kullanarak Güney Afrika'da 1995-2011 yılları arasında eğitim ve sağlık harcamaları ile İnsani Gelişmişlik Endeksi tarafından ölçülen yaşam kalitesi arasındaki ilişkiyi araştırmıştır. Çalışma sonucunda, yaşam kalitesi ile eğitim ve sağlık harcamaları arasında korelasyon ilişkisi tespit etmiştir. Ayrıca eğitim harcamalarının yaşam kalitesini olumlu etkilediği; sağlık harcamalarının ise yaşam kalitesi üzerinde geciktirici bir etkiye sahip olduğunu belirlemiştir.

Kalkınma ile çevre kirliliği ve insan sağlığı arasındaki ilişkiyi araştıran Erden ve Koyuncu (2014), VAR modeli çerçevesinde Granger nedensellik analizi yöntemini kullanarak Türkiye'de 1980-2012 yıllarını araştırmışlardır. Çalışma sonucunda kalkınmanın çevre kirleticisi olan karbon (CO2) artışına neden olduğu, CO2'nin de sağlık harcamalarını arttırdığı sonucuna ulaşmışlardır. Diğer yandan kalkınma ile sağlık harcamaları arasında pozitif yönlü bir ilişki tespit etmişlerdir. Başka bir çalışmada Çelikkaya ve Sezgin (2015), panel veri analizini kullanarak Türkiye'nin 81 ilinde 2008-2012 y1lı verilerini kullanarak fonksiyonel sınıflandırmaya göre kamu harcamaları ve siyasi değişkenler ile sosyo-ekonomik gelişmişlik endeksi arasındaki ilişkiyi araştırmışlardır. Çalışma sonucunda, kamu harcamaları içerisinde yer alan sağlık hizmetlerinin sosyo-ekonomik kalkınma üzerinde anlamlı ve arttırıcı bir etkisi olduğunu tespit etmişlerdir. Başka bir çalışmada Mishra ve Mishra (2015), Toda ve Yamamato nedensellik testini kullanarak 1985-86 y1llarından 2014-15'e kadar olan süreçte Hindistan'da sağlık ve eğitim harcamaları ile ekonomik büyüme arasındaki ilişkiyi araştırmışlardır. Yapmış oldukları çalışma sonucunda, sağlık harcamaları ile ekonomik büyümenin birbirini etkilediğini ve eğitim harcamaları ile ekonomik büyüme arasında tek yönlü bir ilişkinin varlığını belirlemişlerdir. Ayrıca, eğitim harcamalarının sağlık harcamalarında genişlemelere neden olduğunu tespit etmişlerdir. Benzer bir çalışmada Arslan vd. (2016), Augmented Dickey-Fuller ve Phillips- Perron ile Hatemi-J (2012) Asimetrik Nedensellik testi yöntemini kullanarak Türkiye'de 1975-2012 döneminde sağlık ile kalkınma ilişkisini incelemişlerdir. Çalışma 
sonucunda, sağlık göstergeleriyle kalkınma arasında pozitif bir ilişki belirlemişlerdir.

Toplam sağlık harcamalarının İnsani Gelişmişlik Endeksi üzerindeki etkisini araştıran Mirahsani (2016), panel veri analizi yöntemini kullanarak 25 güneybatı Asya ülkesinde 2000-2008 dönemini incelemiştir. Yapmış olduğu çalışma sonucunda, sağlık harcamaları artışının İnsani Gelişmişlik Endeksi'ni arttırdığı sonucuna ulaşmıştır. Benzer bir çalışmada Yalçın ve Çakmak (2016), regresyon analizi yöntemini kullanarak Türkiye'de 1991-2013 döneminde kamu sağlık harcamalarının insani gelişme düzeyi üzerindeki etkisini araştırmışlardır. Çalışma sonucunda, kamu sağlık harcamalarının insani gelişme düzeyi üzerinde anlamlı bir etkisinin olduğu sonucuna ulaşmışlardır. Başka bir çalışmada Kamacı ve Yazıcı (2017), panel veri analizi yöntemini kullanarak 35 OECD ülkesinde 2000-2014 döneminde sağlık harcamaları ile ekonomik büyüme arasındaki ilişkiyi araştırmışlardır. Çalışma sonucunda, sağlık harcamaları ile ekonomik büyüme arasında çift yönlü nedensellik ilişkisi belirlemişlerdir. Başka bir çalışmada Li vd. (2017), panel veri analizi yöntemini kullanarak 2000-2015 yı1ları arasında Çin Shandong Eyaletindeki 17 idari bölgede kamu sağlı harcamaları ile sosyo-ekonomik gelişmişlik arasındaki ilişkiyi araştırmışlardır. Çalışma sonucunda, kişi başına düşen halk sağlığı harcamalarının ve sağlık sigortasının kapsamının sosyo-ekonomik gelişmeyi önemli ölçüde artırabileceğini tespit etmişlerdir. Ayrıca, sağlik kurumlarının artmasının ve büyümesinin ekonomik kalkınmayı teşvik etmediğini hatta personel fazlalığı ve kaynak israfını gibi durumların oluşmasının ekonomik kalkınmayı durdurabileceğini belirtmişlerdir.

Eğitim ve sağlık harcamaları ile ekonomik büyüme arasındaki ilişkiyi araştıran Şen vd. (2018), Bootstrap Panel Granger nedensellik testini kullanarak 8 gelişmekte olan ülkede 1995-2012 dönemini incelemişlerdir. Yapmış oldukları çalışma sonucunda, Brezilya ve Meksika'da eğitim ve sağlık harcamaları ile ekonomik büyümeye doğru anlamlı ve pozitif bir ilişki, Endonezya'da değişkenler arasında anlamlı ve negatif bir nedensellik ilişkisi tespit etmişlerdir. Diğer ülkelerde ise eğitim ve sağlık harcamaları ile ekonomik büyüme arasında nedensellik ilişkisi tespit edememişlerdir. Başka bir çalışmada Nuhu vd. (2018), arac1lık analizini kullanarak 2000-2014 yılları arasında sağlık harcamaları, İnsani Gelişme Endeksi ile anne ve yeni doğan bebek ölümleri ilişkisini araştırmışlardır. Çalışma sonucunda, Afrika'da birçok ülkede anne ve yeni doğan bebek ölümlerinin azaldığını, İnsani Gelişme Endeksi ile anne ve yeni doğan bebek ölümleri arasında negatif ilişki olduğunu tespit etmişlerdir. Ayrıca, sağlık harcamalarının her yıl anne ve yeni doğan bebek ölümleri arasındaki ilişkiye aracılık ettiği sonucuna ulaşmışlardır.

\section{VERI}

$\mathrm{Bu}$ çalışmada 2000-2015 döneminde 34 OECD ülkesinde sağlık harcamaları ile kalkınma arasında uzun dönemli ilişki ile nedensellik araştırılmıştır. Verilerin seçilmesinde çalışmanın hedefi ile literatür esas alınmıştır. Çalışmada yer alan değişkenler Tablo 2'de verilmiş olup, kullanılan veriler Birleşmiş Milletler Kalkınma Programı (United Nations Development 
Programme) ve Dünya Bankası veri tabanından (World Bank) alınmıştır. Kalkınmayı temsilen İnsani Gelişmişlik Endeksi bağımlı değişken; İnsani Gelişmişlik Endeksi üzerinde etkili olan sağlık harcamaları bağımsız değişken olarak kullanılmıştır.

Tablo 2: Analizde Yararlanılan Değişkenler

\begin{tabular}{|c|c|c|}
\hline Değişken Adı & Sembolü & Kaynağı \\
\hline İnsani Gelişmişlik Endeksi & İGE & $\begin{array}{c}\text { United Nations Development Programme } \\
(2018)\end{array}$ \\
\hline Sağlık Harcamaları & SH & World Bank Data (2018) \\
\hline
\end{tabular}

IV. METODOLOJI

Çalışmada panel veri analizinden yararlanılarak 34 OECD ülkesinde sağlık harcamaları ve kalkınma arasındaki uzun dönemli ilişkinin varlığg ile nedensellik ilişkisi incelenmiştir.

Çalışmada öncelikle yatay kesit bağımlılık testi kullanılmış sonrasında yatay kesit bağımlılı̆̆ını dikkate alan panel CADF birim kök testi uygulanmıştır. Birim kök testinin ardından Pesaran ve Yamagata (2008) homojenlik testi yapılmıştır. Daha sonra Westerlund ve Edgerton (2007) testi ile eşbütünleşme ilişkisi ve FMOLS yöntemi ile uzun dönemli ilişkiye bakılmıştır. Sonrasında Dumitrescu ve Hurlin (2012) nedensellik testi uygulanmıştır. Öncelikle ampirik analizde kullanılan testler hakkında bilgi verilmiş ardından test sonuçları değerlendirilmiştir.

Tablo 3'te teorik ile ampirik literatür göz önünde bulunularak değişkenler arasında beklenen ilişki verilmiştir. Çalışmada kullanılan sağlık harcamalarının İnsani Gelişmişlik Endeksi'ni arttırması beklenmektedir. İnsani Gelişmişlik Endeksi içerisinde sağlık bileşeninin yer alması nedeniyle sağlık harcamalarının İnsani Gelişmişlik Endeksi'ni arttırması beklenmektedir.

Tablo 3: Değișkenin Olası Etkisi

\begin{tabular}{|c|c|}
\hline Değişken Adı & Olası Etkisi \\
\hline Sağlık Harcamaları & $(+)$ \\
\hline
\end{tabular}

\section{AMPÍRİK SONUÇLAR}

$\mathrm{Bu}$ çalışmada sadece bir modelin tahmini yapılmıştır. Çalışmada yer alan modelin bağımlı değişkeni İnsani Gelişmişlik Endeksi (IGE); bağımsız değişken olarak sağlık harcamaları (SH) kullanılmıştır. Modelde sağlık harcamalarının İnsani Gelişmişlik Endeksi üzerindeki etkisi incelenmiştir. Model aşağıdaki denklemle verilmiştir:

Model: $\operatorname{IGE}_{2 \mathrm{it}}=\alpha_{\mathrm{it}}+\beta_{1} \mathrm{SH}_{\mathrm{it}}+\mathrm{u}_{\mathrm{it}}$

\section{A. Yatay Kesit Bağımlılı̆̆ı Testi}

Ampirik analiz uygulanırken çalışmada kullanılan değişkenlerin arasında yatay kesit bağımlılığının varlığı durumunda, bu duruma dikkat edilmeden analizin yapılması durumunda çıkan sonuçlar önemli düzeyde etkilenmektedir. $\mathrm{Bu}$ sebeple analiz öncesi serilerde yatay kesit bağımlılığının test edilmesi gereklidir (Pesaran, 2004). 
Yatay kesit bağımlılığı testinde, sabit durumda ve zaman boyutu kesit boyutundan büyükse Breusch ve Pagan (1980) LM testi uygulanır (Baltagi vd., 2012, s. 165). Kesit boyutu zaman boyutundan büyük olduğu zaman Pesaran (2004) $\mathrm{CD}_{\text {LM }}$ testi kullanilır (Denklem 2). Bununla birlikte kesit boyutu ile zaman boyutunun eşit olması durumunda ise Pesaran (2004) $\mathrm{CD}_{\mathrm{LM} 2}$ testi yapılmaktadır. Diğer taraftan Pesaran vd. (2008), heterojen bir panel modelinde sonlu örnek yaklaşımlarını kullanarak önyargı ayarlı bir LM testi geliştirmiştir.

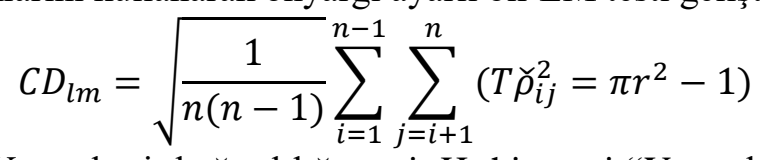

Yatay kesit bağımlılı̆̆ testi, $\mathrm{H}_{0}$ hipotezi "Yatay kesit bağımlılı̆̆ yoktur" şeklinde iken $\mathrm{H}_{1}$ hipotezi "Yatay kesit bağımlılı̆g 1 vardır" şeklindedir. Yatay kesit bağımlılığı test sonuçlarında çıkan olasılık değeri 0.05 'ten küçük olduğu zaman $\mathrm{H}_{0}$ hipotezi \%5 anlamlılık düzeyinde reddedilmekte ve paneli oluşturan serilerin arasında yatay kesit bağımlılığının olduğu sonucuna ulaşılmaktadır (Pesaran vd., 2008). Yatay kesit bağımlılı̆̆ testi sonuçları Tablo 4 'te verilmiştir:

Tablo 4: Yatay Kesit Bağımlılığı Testi Sonuçları

\begin{tabular}{|l|c|c|c|c|}
\hline \multirow{2}{*}{$\begin{array}{l}\text { Değişkenlerde Yatay Kesit } \\
\text { Bağılılı̆̆ }\end{array}$} & \multicolumn{2}{|c|}{ İGE } & \multicolumn{2}{c|}{ SH } \\
\cline { 2 - 5 } & İst. & Olas. & İst. & Olas. \\
\hline CD $_{\text {LM1 }}$ (BP,1980) & 1527.955 & 0.000 & 2113.149 & 0.000 \\
\hline CDLM2 (Pesaran, 2004) & 28.868 & 0.000 & 46.338 & 0.000 \\
\hline CD $D_{\text {LM }}$ (Pesaran, 2004) & 1.742 & 0.041 & -0.042 & 0.483 \\
\hline Bias-Adjusted CD Test & 28.076 & 0.000 & 42.141 & 0.000 \\
\hline
\end{tabular}

Tablo 4'teki sonuçlara bakıldığında, panel genelinde $\mathrm{H}_{0}$ hipotezi "yatay kesit bağımlılığ yoktur" $\% 5$ anlamlllık düzeyinde reddedilmiştir ve seriler arasında yatay kesit bağımlılı̆̆ının olduğu tespit edilmiştir. Bundan dolayı yatay kesit bağımlılığına dikkate eden ikinci nesil birim kök testi kullanılmıştır.

\section{B. CADF Birim Kök Testi}

CADF birim kök testi, kesit anlamında genişletilmiş olan Dickey-Fuller birim kök testi Pesaran (2007) tarafından geliştirilmiştir. Ampirik analizi oluşturan yatay kesit birimleri, seriye gelen bir şok karşısında birbirlerinden etkilenebilmektedir. Analiz sonuçlarının sağlklı çıkması açısından yatay kesit bağımlılı̆̆ına dikkat eden birim kök testi (ikinci nesil birim kök testleri) kullanılmalıdır (Pesaran, 2007).

CADF testiyle, panelde yer alan serilerin her bir yatay kesitinde (örneğin, her ülke için) birim kök testi uygulanabilmektedir. Bu durumda paneldeki serilerin durağanlığını, hem panel geneli için hem de her bir yatay kesit için ayrı şekilde sonuçlarının hesaplanması mümkündür. CADF testi, her yatay kesitin zaman etkisinden farklı şekilde etkilendiğini varsayarak mekânsal otokorelasyona dikkat etmektedir (Pesaran, 2007: 266-267).

CADF testinin regresyon denklemi aşağıda verilmiştir;

$y_{i t}=\left(1-\phi_{i}\right) \mu_{i}+\phi_{i} y_{i, t-1}+u_{i t}, i=1, \ldots ., N ; t=1, \ldots, T \quad u_{i t}={ }^{\prime} \Upsilon_{i} f_{t}+\varepsilon_{i t}$ 
CADF testi, zamanın kesitten büyük olduğu durumda ve kesitin zamandan büyük olduğu durumda uygulanabilmektedir. Testin hipotezleri aşağıda yer almaktadır (Pesaran, 2007: 268).

$H_{0}: \beta_{\mathrm{i}}=0$

(Seri durağan değil)

$H_{1}: \beta_{\mathrm{I}}<0, i=1,2, \ldots, N_{1}, \beta_{1}=0, i=N_{1}+1, N_{1}+2, \ldots, N \quad$ (Seri durağan)

CADF testi sonucu elde edilen CIPS istatistiği (6 nolu Denklem) her yatay kesit amacıyla hesaplanmış olan $t$ istatistiğinin ortalamasının alınması yoluyla bulunmaktadir (Pesaran, 2007: 276).

$$
\operatorname{CIPS}(\mathrm{N}, \mathrm{T})=\mathrm{t}-\text { bar }=\mathrm{N}^{-1} \sum_{\mathrm{i}=1}^{\mathrm{N}} \mathrm{t}_{\mathrm{i}}(\mathrm{N}, \mathrm{T})
$$

CADF Birim kök test sonuçları Tablo 5'te verilmiştir;

Tablo 5: CADF Birim Kök Test Sonuçları

\begin{tabular}{|l|l|l|}
\hline DÜZEY & İGE & SH \\
\hline Sabit İstatistik & $-2.958^{* * * *}$ & -2.114 \\
\hline BíRİNCİ FARK & İGE & SH \\
\hline Sabit İstatistik & $\mathbf{- 3 . 1 8 5 * * *}^{* *}$ & $\mathbf{- 4 . 9 4 1 * * *}^{* *}$ \\
\hline
\end{tabular}

Not: $* \% 10, * * \% 5, * * * \% 1$ anlamlılık düzeyinde sıfir hipotezinin reddedildiğini göstermektedir. Test modeli için sabitli model kullanılmıştır. Sabitte kritik değerler -2.45 (1\%), -2.25 (5\%), -2.14 (10\%).'dir. Kritik değer hesaplamaları için Pesaran (2007) makalesinden faydalanılmışıır.

CADF Birim Kök testi sonuçlarına göre CIPS değerleri incelendiğinde, panel genelinde serilerin düzeyinde durağan olmadıkları için "birim kök vardır" hipotezi reddedilememektedir. Serilerin birinci farkları alındığı zaman durağan (I(1)) oldukları tespit edilmiştir. Seriler durağan hale geldiklerinden dolayı eşbütünleşme testinin uygulanmasına engel bir durum bulunmamaktadır.

\section{Westerlund ve Edgerton (2007) Eşbütünleşme Testi}

Panel eşbütünleşme testine geçmeden önce, eşbütünleşme eğim katsayılarının homojen ya da heterojen olup olmadığını belirlemek için homojenlik testi uygulanmaktadır. Diğer yandan homojenlik testi, serilerin durağanlığının tespitinde ve serilerin arasında eşbütünleşme ilişkisinin var olup olmadığının sınanması için uygulanacak olan testlerin belirlenmesinde etkilidir (Pesaran ve Yamagata, 2008: 56). Testin sıfır hipotezi "eğim katsayıları homojendir" şeklinde iken alternatif hipotez ise "eğim katsayıları homojen değildir" şeklindedir.

Homojenlik testi sonucunda olas1lık değeri 0.10 'dan büyük olduğunda sıfir hipotezi \%10 seviyesinde kabul edilir. Sifir hipotezinin kabul edilmesi durumunda, homojenlik testi sonrasında uygulanacak olan eşbütünleşme testinin sonuçları güvenilir ve geçerlidir (Pesaran ve Yamagata, 2008). Tablo 6'da homojenlik testinin sonuçları verilmiştir. Tablo 6'da yer alan olasılık değerinin 0.10 'dan büyük çıkmasından dolayı sıfır hipotezi kabul edilmiştir. Diğer bir ifadeyle eşbütünleşme denkleminde, sabit terimin ve eğim katsayılarının homojen olduğu sonucuna ulaşılmıştır. 
Tablo 6: Homojenlik Test Sonuçları

\begin{tabular}{|c|c|c|}
\hline & Test İstatistiği & Olasılık Değeri \\
\hline$\tilde{\Delta}$ & -1.443 & 0.926 \\
\hline$\tilde{\Delta}_{\mathrm{adj}}$ & -1.650 & 0.951 \\
\hline
\end{tabular}

Homojenlik testinin ardından değişkenler arasında eşbütünleşme ilişkisi bulunup bulunmadığının belirlenmesi amaciyla Westerlund ve Edgerton (2007) eşbütünleşme testi uygulanmıştır. McCoskey ve Kao (1998) tarafından geliştirilen Lagrange testi çarpanına dayanan eşbütünleşme testi, yatay kesit birimlerinin arasında yer alan bağımlılı̆̆ dikkate alır. Westerlund ve Edgerton (2007) eşbütünleşme testinin küçük örneklemler kullanıldığında da iyi sonuçlar verdiği belirlenmiştir (Westerlund ve Edgerton, 2007: 185-190).

Westerlund ve Edgerton (2007) panel istatistiklerinde kullanılan hipotezler aşağıda verilmiştir:

$\begin{array}{ll}H_{0}^{p}: \alpha_{\mathrm{i}}=0 & \text { (Eşbütünleşme vardır). } \\ H_{A}^{p}: \alpha_{\mathrm{i}}=\alpha<0 & \text { (Eşbütünleşme yoktur). }\end{array}$

Eşbütünleşme testi sonuçları Tablo 7'de verilmiştir:

Tablo 7: Westerlund ve Edgerton (2007) Eşbütünleşme Test

\begin{tabular}{|c|c|c|c|}
\hline Model & LM-İstatistiği & $\begin{array}{c}\text { Asimptotik } \\
\text { Olasılık Değ. }\end{array}$ & $\begin{array}{c}\text { Bootstrap Olasılık } \\
\text { Değ. }\end{array}$ \\
\hline Sabitli Model & 3.018 & 0.001 & 0.651 \\
\hline Sabitli ve Trendli Model & 2.625 & 0.004 & 0.887 \\
\hline
\end{tabular}

Not: Bootstrap olasılık değerleri 10.000 tekrarlı dağılım ile; Asimptotik olasılık değerleri ise standart normal dağılım ile bulunmuştur. Gecikme ile öncül 1 alınmıştır.

Westerlund ve Edgerton (2007) eşbütünleşme testinin sonuçlarına bakıldığında, eşbütünleşmenin olduğuna dair temel hipotez $\% 5$ anlamlılık düzeylerinde kabul edilmektedir.

\section{Panel FMOLS Testi}

Panel eşbütünleşme testi sonrasında değişkenler arasındaki ilişkinin katsayılarını belirlemek üzere test yöntemleri geliştirilmiştir. Pedroni tarafindan geliştirilen FMOLS testi, standart tahmincilerde yer alan (otokorelasyon, değişen varyans vb. sorunlar sonras1 oluşan) sapmaları düzeltebilen bir testtir. FMOLS yönteminin analiz tekniğinin gücünü küçük örnekler ile test eden Pedroni, küçük örnekler sonucu çıkan t istatistik değeri performansı, Monte Carlo simülasyonları ile iyi olduğu sonucuna ulaşmıştır (Gülmez ve Yardımcıoğlu, 2012: 346-347). Test sonuçları Tablo 8'de verilmiştir:

Tablo 8: FMOLS Katsayı Tahmini Sonuçları

\begin{tabular}{|l|l|l|l|}
\hline \multicolumn{4}{|c|}{ Model: İGEit $=\alpha_{\mathrm{it}}+\beta_{1} \mathrm{SH}_{\mathrm{it}}++\mathrm{u}_{\mathrm{it}}$} \\
\hline \multirow{3}{*}{ Değişken } & Katsayı & t istatistik & Olasılık \\
\hline SH & 0.014754 & 10.76825 & $\mathbf{0 . 0 0 0 0 * * * *}$ \\
\hline
\end{tabular}

Not: *\% 10,**\% 5 ve ***\% 1 düzeylerinde istatistiksel olarak anlamlıdır.

Panel FMOLS testi sonuçlarına göre sağlık harcamaları ile İnsani Gelişmişlik Endeksi arasında \%1 seviyesinde anlamlı ve pozitif yönlü bir ilişki 
tespit edilmiştir. Bunun nedeni olarak, insani gelişmenin bileşenlerinden olan sağlık düzeyini sağlık harcamalarının belirlemesi gösterilebilir.

\section{E. Dumitrescu ve Hurlin (2012) Panel Nedensellik Testi}

Çalışmada kullanılan nedensellik testi, Dumitrescu ve Hurlin (2012) tarafindan son dönemde literatüre kazandırılmıştır. Granger (1969) nedensellik testinin geliştirilmiş hali olan Dumitrescu ve Hurlin nedensellik testinin, dengesiz panel veri setlerinde bile etkin sonuçlar çıkarabilmesi en büyük avantajlarından birini oluşturmaktadır. Zamanın kesit boyutundan büyük veya küçük olduğu durumlarda da kullanılabilmesi ve kullanılan seriler arasında yatay kesit bağımlılı̆̆ının varlığına olanak tanıması diğer avantajları olarak sayılabilir (Dumitrescu ve Hurlin, 2012: 1457).

Çalışmada kullanılan değişkenler arasındaki nedensellik ilişkisi Dumitrescu ve Hurlin (2012) nedensellik testi uygulanarak incelenmiştir. Nedensellik testinin yapılabilmesi için serilerin durağan olma şartı bulunduğundan serilerin birinci dereceden farkı kullanılmıştır. Test sonuçları Tablo 9'da verilmiştir:

Tablo 9: Dumitrescu ve Hurlin Nedensellik Testi Sonuçları

\begin{tabular}{|l|l|l|l|l|l|l|}
\hline \multicolumn{7}{|c|}{ Model: İGEit= $\alpha_{\text {it }}+\beta_{1} \mathrm{SH}_{\text {it }}++\mathrm{u}_{\text {it }}$} \\
\hline \multirow{2}{*}{ Değişkenler } & \multicolumn{2}{|l|}{ K=1 } & \multicolumn{2}{|l|}{ K=2 } & \multicolumn{2}{l|}{} \\
\cline { 2 - 7 } & $Z_{N}^{H N C}$ & Olasılık & $Z_{N}^{H N C}$ & Olasılık & $Z_{N}^{H N C}$ & Olasılık \\
\hline SH-İGE & 4.80838 & & 3.73768 & & 3.52049 & $\mathbf{0 . 0 0 0 4 * * *}$ \\
\hline İGE-SH & 2.55752 & $\mathbf{2 . E - 0 6 * * *}$ & & $\mathbf{0 . 0 0 0 2 * * *}$ & & \\
\hline
\end{tabular}

Not: $* \% 10, * * \% 5$ ve ***\% 1 düzeyinde anlamlılı̆̆1 göstermektedir.

Nedensellik testinin sonuçlarına göre sağlık harcamaları ile İnsani Gelişmişlik Endeksi arasında çift yönlü nedensellik ilişkisinin olduğu bulunmuştur. Nedensellik testi sonuçlarında; her birimin aynı gecikme uzunluğuna sahip olması sınırı altında bir, iki ve üçüncü gecikmede benzer sonuçlar tespit edilmesi test sonuçlarının güvenilirlik düzeyini gösterdiği söylenebilir. Başka bir ifadeyle, her üç gecikmede de sağlık harcamaları ile İnsani Gelişmişlik Endeksi arasında çift yönlü nedensellik ilişkisinin varlığı tespit edilmiştir.

Nedensellik sonuçları değerlendirildiğinde; sağlık harcamaları ile İnsani Gelişmişlik Endeksi arasındaki çift yönlü nedensellik ilişkisinin sebebi olarak; sağlık harcamaları tarafından belirlenen sağlık düzeyinin İnsani Gelişmişlik Endeksi bileşenlerinden olması ile insani gelişmenin yaşanması sonucunda refah artışı ile birlikte sağlık harcamalarına yönelik talebin artabileceği ifade edilebilir.

Literatürde, Mirahsani (2016) ile Kamacı ve Yazıcı (2017) panel veri analizinin uygulayarak bulmuş olduğu sonuçlar bu çalışmanın sonuçlarını destekler niteliktedir. $\mathrm{Bu}$ çalışmada OECD ülkelerinde sağlık harcamaları ile kalkınma ilişkisinin incelenmesi; ekonometrik analizde üstün testlerin kullanılması nedeniyle literatüre katkı sağlayacağı düşünülmektedir. 


\section{SONUÇ}

Sağlık harcamaları bireylerin ve böylece toplumun refahı ile ilgili bir kavram olarak ülkelerin kalkınma sürecine destek sağlamaktadır. Sağlık harcamalarına ve politikalarına bağlı olarak birey ve toplum sağlığı iyileşmekte ve ülkenin beșeri kaynağı açısından önem taşımaktadır.

Sağlıklı bir toplumun varlığı sonucunda; ülkede ekonomik, sosyal, kültürel vb. anlamda gelişmeler yaşanabilmektedir. Artan sağlık harcamaları ile insani yaşam kalitesinde ve yaşam süresinde iyileşmeler ile birlikte bireyler ülke gelişmesine katkı sunabilmektedir. Ülkelerin yatırım, üretim vb. süreçleri sağlıklı bir toplum ile daha da ileri aşamalara taşınabilmekte ve refah düzeyine bağlı olarak sosyal, kültürel gelişmeler yaşanabilmektedir. Bu durumun sonucunda da ülkenin gelişmişlik düzeyi artış gösterebilmektir. Bu nedenle ülkelerin kalkınma sürecinde sağlık harcamalarının rolünü tespit etmek önem taşımaktadır.

Çalışmada panel veri analizinden yararlanılarak 34 OECD ülkesinde 2000-2015 yılları arasında sağlık harcamaları ile kalkınma arasındaki ilişki incelenmiştir. Yapılan çalışma sonucunda, sağlık harcamalarının kalkınmayı pozitif etkilediği tespit edilmiştir. Ayrıca sağlık harcamaları ile kalkınma arasında çift yönlü nedensellik ilişkisi tespit edilmiştir. Buradan hareketle ülkelerin sağlık harcamaları ile ilgili çeşitli düzenlemelerde bulunmalarının kalkınma süreçlerine katkıda bulunabileceği ifade edilebilir. $\mathrm{Bu}$ düzenlemeler aşağıdaki gibi siralanabilir;

$>$ Sağlık harcamaları insani bir yatırım olması nedeniyle beşeri unsurlar arasında önemli bir yer tutmaktadır. Kalkınma açısından önem taşıyan beşeri sermayenin arttırılmasında eğitim kadar sağlık harcamalarının etkisi büyüktür. Ancak bütçe kısıtı nedeniyle harcamaları istenen düzeye çekmek her zaman mümkün olmamaktadır. Bu nedenle bütçe kısıtı göz önünde bulundurularak ülkelerin sağlık harcamalarına önem vermeleri veya sağlık harcamalarını arttırmaları ülkelerin kalkınma sürecine destek olabileceği söylenebilir.

Bireylerin insani yaşam kalitesi ve ortalama yaşam ömründe belirleyici unsur olan sağlık harcamaları refah kavramı ile yakın ilişki içindedir. Ülke refahının iyileşmesi ile birlikte kalkınma sürecinde önemli mesafeler kat edilebilmektedir. Buradan hareketle ülke refahının arttırılmasında önemli olan sağlık sektörünün gelişmesinin kalkınma sürecine katkı sunabileceği ifade edilebilir.

Ülkelerin sağlık harcamalarını kalite yönünden ve rakamsal anlamda iyileştirmeleri sonucunda sağlık hizmetlerinin bireylere faydası artabilecektir. Bireylerin daha kaliteli ve yeterli sağlık hizmetler alması sonucunda toplumsal gelişme ile birlikte kalkınmanın KAYNAKÇA sağlanmasında önemli rol oynayabileceği ileri sürülebilir.

Alin, O. \& M. D. Marieta (2011). Correlation Analysis Between the Health System and Human Development Level Within the European Union, International Journal of Trade, Economics and Finance, 2(2), 99-102. 
Arslan, İ. \& M. V. Eren \& S. Kaynak (2016). Sağlık ile Kalkınma Arasındaki İlişkinin Asimetrik Nedensellik Analizi, Dokuz Eylül Üniversitesi İktisadi ve İdari Bilimler Fakültesi Dergisi, 31(2), 287-310.

Baltagi, B. H. \& F. Moscone (2010). Health Care Expenditure and Income in the OECD Reconsidered: Evidence From Panel Data, IZA Discussion Paper, No: 4851.

Baltagi, B. H. \& Q. Feng \& C. Kao (2012). A Lagrange Multiplier Test for Cross-Sectional Dependence in a Fixed Effects Panel Data Model, Journal of Econometrics, 170(1), 164177.

Breusch, T. S. \& A. R. Pagan (1980). The Lagrange Multiplier Test and İts Applications to Model Specification in Econometrics, The Review of Economic Studies, 47(1), 239-253.

Çelikkaya, S. \& A. Sezgin (2015). Kamu Harcamalarının Kalkınmaya Olan Etkileri: Türkiye Örneği, Mehmet Akif Ersoy Üniversitesi İktisadi ve İdari Bilimler Fakültesi Dergisi, 1(2), 40-59.

Dumitrescu, E. I. \& C. Hurlin (2012). Testing for Granger non-Causality in Heterogeneous Panels, Economic Modelling, 29(4), 1450-1460.

Erden, C. \& F. T. Koyuncu (2014). Kalkınma ve Çevresel Sağlık Riskleri: Türkiye İçin Ekonometrik Bir Analiz, Aksaray Üniversitesi İktisadi ve İdari Bilimler Fakültesi Dergisi, 6(2), 9-23.

Gönel, F. D. (2013). Kalkınma Ekonomisi (2. Baskı), Ankara: Efil Yayınevi.

Gyimah-Brempong, K., \& Wilson, M. (2004). Health Human Capital and Economic Growth in Sub-Saharan African and OECD Countries, The Quarterly Review of Economics and Finance, 44(2), 296-320.

Granger, C. W. (1969). Investigating Causal Relations by Econometric Models and Cross-Spectral Methods, Econometrica, Journal of the Econometric Society, 424-438.

Gülmez, A. \& F. Yardımcıoğlu (2012). OECD Ülkelerinde Ar-Ge Harcamaları ve Ekonomik Büyüme İlişkisi: Panel Eşbütünleşme ve Panel Nedensellik Analizi (1990-2010), Maliye Dergisi, 163, 335-353.

Günsoy, G. (2005). İnsani Gelişme Kavramı ve Sağlıklı Yaşam Hakkı, ZKÜ Sosyal Bilimler Dergisi, I, 35-52.

Heshmati, A. (2001). On the Causality Between GDP and Health Care Eexpenditure in Augmented Solow Growth Model, SSE/EFI Working Paper Series in Economics and Finance, (No. 423).

Human Development Report. (2016). United Nations Development Programme. New York. http://hdr.undp.org/en/2016-report Accessed on: 13.07.2018.

İlkin, A. (1983). Sanayi ve Kalkınma Ekonomisi, İstanbul: Güryay Matbaası.

Jha, R. \& B. Biswal \& U. D. Biswal (2001). An Empirical Analysis of the Impact of Public Expenditures on Education and Health on Poverty in Indian States, Working Papers 998, Queen's University, Department of Economics.

Kamacı, A. \& H. U. Yazıcı (2017). OECD Ülkelerinde Sağlık Harcamalarının Ekonomik Büyüme Üzerindeki Etkisinin Ekonometrik Analizi, Sakarya İktisat Dergisi, 6(2), 52-69.

Li, L., Wu, M., \& Wu, Z. (2017). The Impact of Public Health Expenditure on Economic Development-Evidence from Prefecture-Level Panel Data of Shandong Province, Research in World Economy, 8(2), 59-65.

McCoskey, S. \& C. Kao (1998). A Residual-Based Test of The Null of Cointegration in Panel Data, Econometric Reviews, 17(1), 57-84.

Mirahsani, Z. (2016). The Relationship Between Health Expenditures and Human Development Index, Journal of Research \& Health, Social Development \& Health Promotion Research Center, Vol. 6, No. 3, Jul \& Aug, 373- 377. DOI: 10.7508/jrh.2016.03.011.

Mishra, P. K. \& S. K. Mishra (2015). The Triangulation Dynamics between Education, Health and Economic Growth in India, The Journal of Commerce, 7(2), 69-89.

Mpofu, R. T. (2013). Standard of Living, Quality of Life And Per Capita GDP: A South African Experience, Corporate Ownership \& Control / Volume 11, Issue 1, 882-889. 
Nuhu, K. M., McDaniel, J. T., Alorbi, G. A., \& Ruiz, J. I. (2018). Effect of Healthcare Spending on the Relationship Between the Human Development Index and Maternal and Neonatal Mortality, International Health, 10(1), 33-39.

Pedron1, P. (2000). Full Modified OLS for Heterogeneous Cointegrated Panels, Advances in Econometrics, 15, pp. 93-130.

Pesaran, M. H. (2004). General Diagnostic Tests for Cross Section Dependence in Panels, CESifo Working Paper Series, 1229.

Pesaran, M. H. (2007). A Simple Panel Unit Root Test in the Presence of Cross-Section Dependence, Journal of Applied Econometrics, 22(2), 265-312.

Pesaran, M. H. \& T. Yamagata (2008). Testing Slope Homogeneity in Large Panels, Journal of Econometrics, 142(1), 50-93.

Pesaran, M. H. \& A. Ullah \& T. Yamagata (2008). A Bias Adjusted LM Test of Error Cross Section İndependence, The Econometrics Journal, 11(1), 105-127.

Razmi, S. M. J. \& E. Abbasian \& S. Mohammadi (2012). Investigating the Effect of Government Health Expenditure on HDI in Iran, Journal of Knowledge Management, Economics and Information Technology, Issue 5, https://pdfs.semanticscholar.org/32ee/5b8b2383f5af001257b90b6fba0908e9bbfd.pdf Accessed on: 01.07.2018

Srinivasan, T.N. (1999). İnsani Gelişme Yeni Bir Paradigma mı, Yoksa Tekerleğin Yeniden İcadı mı?, Ş. S. Nartgün (Çev.), Ankara Üniversitesi Eğitim Bilimleri Fakültesi Dergisi, XXXII, 309-312.

Suescún, R. (2007). The Role of Fiscal Policy in Human Development and Growth, LAC Regional.

Şen, H. \& A. Kaya \& B. Alpaslan (2018). Eğitim, Sağlık ve Ekonomik Büyüme İlişkisi: Gelişmekte Olan Ülkeler için Bootstrap Panel Granger Nedensellik Analizi, Sosyoekonomi, 26(36), 125-144.

Todaro, M.P. \& S.C. Smith (2011). Economic Development. (Eleven Edition), Boston: Pearson Education.

United Nations Development Programme (2018). Human Development İndex, http://hdr.undp.org/en/data Accessed on: 01.07.2018.

Westerlund, J. \& D. L. Edgerton (2007). A Panel Bootstrap Cointegration Test, Economics Letters, 97(3), 185-190.

World Bank (2018). Current health expenditure (\% of GDP) World Development Indicators, http://databank.worldbank.org/data Accessed on:01.07.2018.

World Health Organization (2014). WHO Global Health Expenditure Atlas, September. http://www.who.int/health-accounts/atlas2014.pdf Accessed on:13.07.2018.

Yalçın, A. Z. \& F. Çakmak (2016). Türkiye'de Kamu Sağlık Harcamalarının İnsani Gelişim Üzerindeki Etkisi, Atatürk Üniversitesi İktisadi ve İdari Bilimler Dergisi, 30(4), 705-723.

Yardımcıoğlu, F. (2012). OECD Ülkelerinde Sağlık ve Ekonomik Büyüme İlişkisinin Ekonometrik Bir İncelemesi, Eskişehir Osmangazi Üniversitesi Sosyal Bilimler Dergisi, 13(2), 27-47.

Yıldız, F. (2016). Küresel Kamusal Mallar Perspektifinden Barış ve Kalkınma İlişkisi Üzerine Ampirik Bir Analiz, Dumlupınar Üniversitesi Sosyal Bilimler Dergisi, (48), 64-78.

\section{SUMMARY}

Health expenditures are a type of human investment, they affect the life quality and life of individuals. As a result of the existence of individuals with increased quality of life and lifespan, a healthier society is formed and this has a critical importance for the country. The existence of healthy individuals in the country, and thus the existence of society, shows the state of human capital, which plays an active role in the development process. Adequate health expenditures are important in terms of welfare and can contribute to the development process of the country in various ways. The existence of a healthy generation means better jobs in all public and private employment units of the 
country; economic, social, political, social, cultural, etc. better plans, projects, programs, policies will contribute to the emergence of areas. Due to the importance of health expenditures in the development of countries, it is important to determine the role played by the development process.

As a result of health expenditures, which have an important place among public expenditures in developed countries, the existence of a good health system and healthy societies can generally be mentioned. However, health spending in developing countries is not at the desired level. In some developing countries, due to the shortage of resources, the desired level of health expenditure is not realized and as a result serious problems may occur in the health field. On the other hand, the lack of access to basic nutrients and the presence of unhealthy conditions lead to insufficient health expenditures. Countries give importance to health expenditures in general but they can do this in case of budget constraint. However, the World Health Organization, which is active in the field of health in the international sense, works for a healthier world.

For this purpose, the impact of health expenditures on development between 2000 and 2015 in 34 OECD countries was examined by panel data analysis. As a result of this study, since the cross-sectional dependence between the series was determined, the second generation unit root test was used and it was determined that the series became stationary the first aware. According to the results of homogeneity test, it was concluded that the series were homogeneous and a long-term cointegration relationship was found between the variables. According to FMOLS test results, health expenditures have a positive effect on development. On the other hand, it has been concluded that there is a bidirectional causality relationship between health expenditures and development. Based on the results of the study, it can be argued that greater attention to health expenditures and the development of more comprehensive policies to improve health expenditures will contribute to the development process. 